\title{
PENGARUH SELF-HYPNOSIS TERHADAP INTENSITAS NYERI DAN TINGKAT KECEMASAN LANSIA PENDERITA OSTEOARTRITIS
}

\author{
THE EFFECT OF SELF-HYPNOSIS ON PAIN INTENSITY AND ELDERLY ANXIETY LEVEL \\ OF OSTEOARTRITICAL PATIENTS
}

\author{
Chandra Irawan, Aris Sudiyanto, Moh. Fanani \\ Program Studi Magister Kedokteran Keluarga Minat Utama Ilmu Biomedik Universitas Sebelas Maret \\ Surakarta. \\ Korespondensi: dr. Chandra Irawan, Sp. KJ. Email: ch4ndra_dr@yahoo.com
}

\begin{abstract}
ABSTRAK
Radang sendi atau rematik pada lansia disebut osteoartritis bersifat menahun dan tidak bisa sembuh. Nyeri menjadi gejala utama pada sendi yang mengalami osteoartritis. Nyeri tersebut dapat mengganggu fungsi motorik, gangguan tidur dan stres psikologi. Selama ini terapi nyeri lansia penderita osteoartritis adalah dengan farmakoterapi. Karena gangguan psikologi seperti cemas dan depresi berperan dalam kekambuhan nyeri, maka ada intervensi terapi pelengkap yaitu self-hypnosis. Self-hypnosis sebagai terapi pelengkap popular dan familiar karena mudah dilakukan, murah dan bisa dilakukan di rumah secara mandiri. Tujuan dalam penelitian ini untuk mengetahui pengaruh self-hypnosis terhadap intensitas nyeri dan tingkat kecemasan lansia penderita osteoartritis. Studi ini merupakan penelitian kuantitatif berbentuk quasi eksperimental randomizedpretest-posttestcontrol group design, menggunakan modul intervensi self-hypnosis untuk menurunkan intensitas nyeri dan tingkat kecemasan lansia penderita osteoartritis. Studi ini telah mendapat persetujuan dari komite etik rumah sakit. Hasil penelitian ini terdapat perbedaan yang bermakna nilai pretest dan posttest kelompok perlakuan nyeri dan kecemasan lansia osteoartritis. Nilai rerata NRS (nyeri) kelompok perlakuan pretest sebesar 1,47 $\pm 0,57$ dan posttest sebesar 0,97 $\pm 0,72$ dengan nilai $p=0.001<0.05$. Nilai rerata TMAS (cemas) kelompok perlakuan pretest sebesar 13,13 $\pm 2,27$ posttest sebesar 10,93 \pm 3,35 dengan nilai $p=0.000$
\end{abstract}

Kata Kunci: Self-Hypnosis, Intensitas Nyeri, Tingkat Kecemasan, Lansia Penderita Osteoartritis.

\begin{abstract}
Arthritis or rheumatism in the elderly (called osteoarthritis) is chronic and can not be recovered. Pain becomes the main symptoms of osteoarthritis joints experience. The pain can disrupt motor function, sleep disorders and psychological stress. Nowadays, the treatment for elderly with osteoarthritis pain therapy is to pharmacotherapy. Due to psychological disorders such as anxiety and depression play a role in the recurrence of pain, then there is a complementary therapy intervention that is self-hypnosis. Self-hypnosis (as a complementary therapy) popular and familiar because it is easy to do, inexpensive and can be done at home independently. The aimed of this study was to find out whether there is any influence of self-hypnosis on the pain intensity and level of anxiety elderly with osteoarthritis.This study was a quantitative research in the form of quasi experimental randomized pretest-posttest control group design, intervention module using self-hypnosis to reduce pain intensity and level of anxiety elderly with osteoarthritis. This study was approved by the hospital ethics committee. The result of this study was a significant difference in the value pretest and posttest group treated osteoarthritis pain and anxiety elderly. The mean value of NRS (pain) treatment group pretest posttest $1,47 \pm 0.57$ and $0.97 \pm 0.72$ with $p=0.001>0.05$. The mean value of TMAS (anxiety) treatment group pretest amounted to $13.13 \pm 2.27$ posttest $10.93 \pm 3.35$ with $p=0.000$
\end{abstract}

Keywords: Self-Hypnosis, Pain Intensity, Level Of Anxiety, The Elderly With Osteoarthritis.

How To Cite: Irawan, C., Sudiyanto, A.,\& Fanani, M. (2019). PENGARUH SELF-HYPNOSIS TERHADAP INTENSITAS NYERI DAN TINGKAT KECEMASAN LANSIA PENDERITA OSTEOARTRITIS. Biomedia, 11(1), 24-29. doi:https://doi.org/10.23917/biomedika.v11i1.6606

DOI: https://doi.org/10.23917/biomedika.v11i1.6606

\section{PENDAHULUAN}

Berdasarkan Susenas (Survei Ekonomi Nasional) oleh BPS tahun 2012, keluhan kesehatan yang paling tinggi adalah jenis keluhan lainnya $(32,99 \%)$. Jenis keluhan lainnya di antaranya keluhan yang merupakan efek dari 
penyait kronis seperti asam urat, radang sendi atau rematik, darah tinggi, diabetes. Kemudian jenis keluhan yang juga banyak dialami lansia adalah batuk $(17,81 \%)$ dan pilek $(11,76 \%)$ (Komnas Lansia, 2013).

Rematik pada lansia disebut juga Osteoartritis, yakni kerusakan tulang rawan sendi disebabkan proses degenerasi sendi. Penting untuk diketahui bahwa Penyakit osteoartritis tidak dapat sembuh namun hanya dapat dikontrol agar terhindar dari kerusakan sendi lebih lanjut (Indonesian Rheumatology Association (IRA), 2014).

Nyeri menjadi gejala utama pada sendi yang mengalami osteoartritis.Rasa nyeri dapat mengganggu fungsi motorik, gangguan tidur, dan stres psikologis. Bila nyeri terjadi secara kronis, maka dapat menimbulkan keputusasaan, mudah tersinggung atau marah, menarik diri, dan kecemasan (Soejono et al., 2009; Isbagio, 2001)

Pada lansia dengan penyakit kronik dengan osteoartritis memiliki persepsi, pengalaman nyeri yang dapat mengganggu kondisi mental lansia.

Gangguan mental lansia disebabkan pula riwayat nyeri yang pernah dirasakan.Pengalaman nyeri menjadi faktor penentu perubahan psikologis, nyeri yang bersifat hilang timbul dengan intensitas tinggi dan kuantitas yang lebih sering hingga menganggu aktivitas menjadikan perubahan psikologis responden semakin memburuk. Menurunnya fungsi gerak pada usia lanjut akan memberikan dampak pada kebiasaan dalam aktivitas kehidupan sehari-hari. Dampak dari perubahan tersebut adalah timbulnya stres pada lansia.(Permana et al., 2009)

Self-hypnosis berarti menghipnosis diri sendiri.Self-hypnosis merupakan suatu teknik yang sederhana yang dapat membantu kita untuk mengenali pikiran bawah sadar, sekaligus melakukan pemberdayaan diri melalui pemrograman ulang terhadap pikiran bawah sadar tersebut. Pemahaman mengenai Selfhypnosis diharapkan juga dapat menjadi jembatan bagi pemahaman terhadap dunia hipnosis \& hipnoterapi secara utuh, karena sesungguhnya semua peristiwa hipnosis pada dasarnya adalah peristiwa Self-hypnosis (Nurindra, 2008). Selfhypnosis digunakan secara luas dalam hipnoterapi modern. Dia dapat digunakan untuk menolong manajemen nyeri (Patterson, 2010) dan kecemasan (Holand, 2001).

Dari sebuah review terhadap penelitian prospektif terkontrol hipnosis untuk penatalaksanaan nyeri kronik di AS didapatkan bahwa intervensi hipnosis secara konsisten menghasilkan penurunan nyeri yang signifikan pada bermacam-macam permasalahan nyeri kronis (Blair, 2004).

Hipnosis telah menjadi diakui sebagai pengobatan berpotensi efektif bagi banyak individu dengan kecemasan terutama pada lansia dengan osteoarthritis. Beberapa studi terbaru menunjukkan bahwa lebih efektif daripada terapi perilaku-kognitif, yang merupakan pendekatan terapi yang paling umum dalam mengobati kecemasan klinis.

Self-hypnosis untuk kecemasa lansia dengan osteoarthritis dapat membantu mengatasi penyebab yang mendasari serta membantu menemukan perilaku koping yang lebih efektif. Hal ini juga dapat membantu lansia mencapai suasana hati yang bahagia dan mengurangi atau menghilangkan pikiran pesimis dan negatif serta rasa nyeri yang umumnya menyertai kecemasan lansia penderita osteoartritis.

Kebaruan penelitian ini cukup baik karena belum pernah ada penelitian yang mengkaji pengaruh Self-hypnosis terhadap intensitas nyeri dan kecemasan pada lansia penderita osteoartritis.

\section{METODE}

Penelitian ini menggunakan quasi eksperimental pretest-posttest control group design yang ditujukan untuk mengetahui hasil uji akhir dengan mengendalikan hasil uji awal sebagai cara mengendalikan kovariabel

Penelitian dilakukan di Bagian Rehabilitasi Medis RS. X Surakarta, mulai bulan Desember 2016 sampai dengan Januari 2017. Subjek penelitian adalah semua pasien lansia dengan osteoarthritis baru atau lama, unilateral maupun bilateral dengan gejala khusus nyeri dan cemas yang didiagnosis oleh dokter poliklinik RS. X Surakarta dan memenuhi kriteria inklusi dan ekslusi penelitian.

Pengambilan sampel dengan purposive sampling yaitu dilakukan dengan memilih subjek yang keterwakilannya sudah ditentukan berdasarkan kriteria inklusi penelitian sebanyak 40 sampel.

\section{Pengambilan data}

Terapis memberikan instruksi sederhana tentang bagaimana mempelajari Self-hypnosis dan sebuah skrip Self-hypnosis yang dapat direkam untuk klien sendiri (Blair, 2004), dengan face validity dan content validity yang telah dilakukan intereter oleh dua orang pakar psikoterapi (psikiater). 
Lalu pengambilan data melalui Intensitas nyeri merupakan intensitas beratnya nyeri, diukur dengan skor NRS (Numeric Rating Scale) dengan skala $0-10$.

Dan pengambilan data terhadap Kecemasan, cemas adalah skor yang diukur dengan TMAS (Taylor Manifest Anxiety Scale) dengan penjelasan sebagai berikut: skor $<20$ merupakan kecemasan ringan, skor 20-25 merupakan kecemasan sedang, skor > 25 merupakan kecemasan berat (Sudiyanto, 2002).

\section{Instrumen Penelitian dan Cara kerja} Instrumentyang digunakan dalam

penelitian ini adalah:

1. Isian data pribadi

2. Lembar data isian demografi

3. Lembar Informed Consent

4. Instrumen NRS untuk nyeri

5. Instrumen TMAS untuk cemas

6. Modul Self-Hypnosis untuk menurunkan intensitas nyeri lansia dengan osteoarthritis.

Cara kerja yang dilakukan yaitu

1. Pengisian data pribadi

2. Pengisian persetujuan penelitian

3. Pembagian kelompok perlakuan Self-hypnosis dan kelompok kontrol secara acak sederhana.

4. Pengukuran intensitas nyeri dan tingkat kecemasan pre-test pada peserta.

5. Kelompok perlakuan diberi Self-hypnosis setiap hari selama satu bulan dan dilakukan evaluasi setiap minggu sekali.

6. Pengukuran intensitas nyeri dan tingkat kecemasan post-test pada peserta.

7. Menganalisis hasil secara statistik.

\section{Teknik Analisis Data}

Data yang terkumpul akan diolah dan dianalisis menggunakan program SPSS versi 17.0. Uji analisa data antara lain uji kenormalan data dengan Kosmogorov Smirnov Test, uji homogenitas data dengan Levene's Test, uji beda sebelum dengan sesudah kelompok perlakuan 1 dan kelompok kontrol menggunakan uji statistik Paired Samples Test (Sastroasmoro and Ismail, 2006).

Batasan uji kemaknaan statistik adalah: uji kenormalan data dengan Kosmogorov Smirnov Test bila p> 0,05 maka data berdistribusi normal, uji homogenitas data dengan Levene's Test bila p>0,05 maka data homogen, uji beda sebelum dan sesudah tindakan menggunakan paired samples test bila nilai $\mathrm{p}<$ 0,05 berarti ada perbedaan bermakna.

\section{HASIL DAN PEMBAHASAN}

Jumlah sampel sebanyak 60 pasien yang terbagi menjadi dua kelompok yaitu kelompok kontrol 30 pasien terapi standard nyeri jenis NSAID dengan dosis sama dan kelompok perlakuan 30 pasien dengan terapi standard an self-hypnosis.

Perolehan data mengenai karakteristik pasien dapat diliha pada tabel 1 .

Tabel 1. Deskripsi Data Penelitian

\begin{tabular}{lccc}
\hline \multicolumn{1}{c}{ Karakteristik } & \multicolumn{2}{c}{ Kelompok } & $p$ \\
& Kontrol & Perlakuan & \\
\hline Umur & $70.87 \pm 6.40$ & $70.17 \pm 7.11$ & 0.690 \\
BMI & $25.22 \pm 4.53$ & $25.58 \pm 4.03$ & 0.942 \\
Pendidikan & & & \\
$\quad$ SD & $2(6.7 \%)$ & $3(10.0 \%)$ & \\
$\quad$ SMP & $10(33.3 \%)$ & $11(36.7 \%)$ & \multirow{2}{*}{0.942} \\
$\quad$ SMA & $15(50.0 \%)$ & $13(43.3 \%)$ & \\
$\quad$ Sarjana & $3(10.0 \%)$ & $3(10.0 \%)$ & \\
Pekerjaan & & & \\
$\quad$ Swasta & $2(6.7 \%)$ & $4(13.3 \%)$ & \\
$\quad$ Pensiunan & $19(63.3 \%)$ & $17(56.7 \%)$ & 0.678 \\
$\quad$ Wiraswasta & $9(30.0 \%)$ & $9(30.0 \%)$ & \\
Jenis Kelamin & & & \\
$\quad$ Laki-laki & $9(6.7 \%)$ & $10(33.3 \%)$ & \multirow{2}{*}{0.781} \\
$\quad$ Perempuan & $21(6.7 \%)$ & $20(66.7 \%)$ & \\
\hline
\end{tabular}

Pada tabel 1 telah tercantum bahwa rerata umur pasien osteoartritis pada kelompok kontrol sebesar 70,87 $\pm 6,40$ dan rerata umur pada kelompok perlakuan sebesar $70,17 \pm 7,11$ dengan nilai $p=0,690$.

Pada BMI nilai rerata kelompok kontrol sebesar 25,22 $\pm 4,53$ dan nilai rerata kelompok perlakuan sebesar 25,58 $\pm 4,03$ dengan nilai $p=$ 0,744 . Mengenai pendidikan pasien untuk kelompok kontrol yang terbanyak adalah SMA 15 orang $(50 \%)$ dan terendah SD sebanyak 2 orang $(6,7 \%)$, sedangkan pada kelompok perlakuanpendidikan SMA sebanyak 13 (43,3\%), nilai $p=0.942$.

Untuk pekerjaan pasien pada kelompok kontrol sebagian besar adalah pensiunansebanyak 19 orang $(63,3 \%)$ dan kelompok perlakuan sebanyak 17 orang $(56,7 \%)$, nilai $p=0.678$. Pasien yang diperoleh pada penelitian ini yang terbanyak adalah perempuan pada kelompok kontrol diperoleh sebanyak 21 orang $(70,0 \%)$ dan kelompok perlakuan sebanyak 20 orang $(6,7 \%)$ dengan nilai $p=0,781)$. Oleh karena nilai $p>0.05$ maka data untuk karakteritik responden mempunyai varians yang homogen.

Perolehan data mengenai rerata nilai pretest dan postestkelompok kontrol dan perlakuan pasien lansia penderita osteoartritis dengan gejala nyeri dapat dilihat pada gambar 1 . 


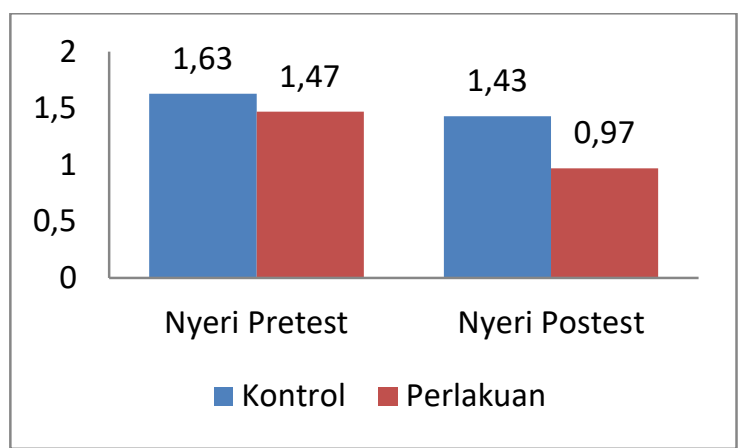

Gambar 1. Perubahan Rerata Nilai NRS pretest dan posttest kelompok kontrol dan kelompok perlakuan

Dari gambar 1 diperoleh data nilai rerata pretest sebesar 1.63 dan posttest sebesar 1.43 pada kelompok kontrol. Selisih nilai rerata pretest dan posttest sebesar 0.2. Pada kelompok perlakuan diperoleh data nilai rerata pretest sebesar 1.47 dan nilai rerata posttest sebesar 0.97 dengan selisih nilai rerata pretest dengan posttest sebesar 0.5. Jadi selisih nilai rerata pretest dengan posttest kelompok kontrol lebih kecil dibandingkan selisih nilai rerata pretest dengan posttest kelompok perlakuan.Juga berlaku sebaliknya.

Perolehan data mengenai nilai pretest dan posttest kelompok kontrol dan perlakuan pasien lansia penderita osteoartritis dengan gejala kecemasan dapat dilihat pada gambar 2 .

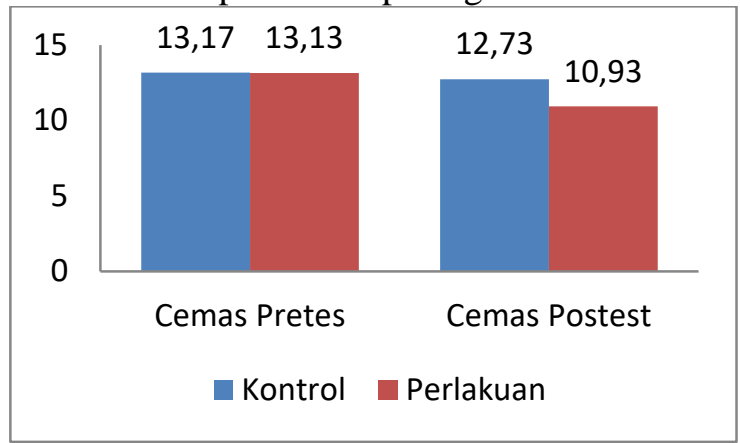

Gambar 2. Perubahan Nilai TMAS pretest dan posttest kelompok kontrol dan kelompok perlakuan.

Dari gambar 2 diperoleh data nilai rerata pretest 13.17 dan nilai rerata posttest 12.73 pada kelompok kontrol. Selisih nilai rerata pretest dengan posttest kelompok kontrol sebesar 0.44.Sedangkan pada kelompok perlakuan diperoleh data rerata pretest 13.13 dan nilai rerata posttest 10.93 dengan selisih sebesar 2.20.Jadi selisih nilai rerata pretest dengan posttest kelompok kontrol lebih kecil dibandingkan selisih nilai rerata pretest dengan posttest kelompok perlakuan.Juga berlaku sebaliknya.

\section{Uji Normalitas}

Dalam penelitian ini uji normalitas data menggunakan Kolmogorov Smirnov terhadap variabel penelitian data NRS dan TMAS pada kelompok perlakuan dan kelompok kontrol.

Data nyeri (NRS) pada kelompok pretest dan postest mempunyai nilai $p=0.000(p<0.05)$ yang berarti data tidak berdistribusi normal sehingga untuk uji analisis digunakan non parametrik yaitu Mann-Whitney Test. Nilai pretest pada TMAS (cemas) sebesar $p=0.055(\mathrm{p}>$ 0.05 ) dan postest mempunyai nilai $p=0.155$ ( $p>$ 0.05 ), oleh karena nilai $p>0.05$ maka data TMAS berdistribusi normal, sehingga uji analisis yang digunakan independen $t$ test.

\section{Uji Kesetaraan Data Pretest}

Uji kesetaraan data digunakan untuk melihat apakah data sama sebelum adanya perlakuan antara kedua kelompok pada penelitian tersebut. Hasil uji kesetaraan dapat dilihat pada tabel 2 .

Tabel 2. Uji Kesetaraan Data NRS dan TMAS

Kelompok Perlakuan dan Kontrol Pretest

\begin{tabular}{ccccc} 
Variabel & Kelompok & $\mathbf{N}$ & Rerata & $\boldsymbol{p}$ \\
\hline NRS Postest & Perlakuan & 30 & $0.97 \pm 0.72$ & \multirow{2}{*}{0.011} \\
& Kontrol & 30 & $1.43 \pm 0.57$ & \\
TMAS Postest & Perlakuan & 30 & $10.93 \pm 3.53$ & \multirow{2}{*}{0.020} \\
& Kontrol & 30 & $12.73 \pm 2.13$ &
\end{tabular}

Berdasarkan tabel 2 diperoleh $p$-value pada NRS pretest sebesar 0,198 dan p-value TMAS pretest sebesar 0,952 , oleh karena nilai $p>$ 0.05 maka data NRS dan TMAS untuk pretest antara perlakuan dengan kontrol adalah setara.

\section{Uji Beda NRS (Nyeri) dan TMAS (Kecemasan) Antara Kelompok Perlakuan dengan Kelompok Kontrol Data Postest \\ Uji Beda NRS (Nyeri) dan TMAS} (Kecemasan) antara kelompok perlakuan dengan kelompok kontrol data postest tersaji pada tabel 3. Pada tabel ini didapatkan nilai rerata NRS postest kelompok perlakuan sebesar 0,97 $\pm 0,72$ kelompok kontrol sebesar 1,43 \pm 0.57 dengan nilai $p=0.011(p<0.05)$ yang berarti ada perbedaan yang bermakna antara kelompok kontrol pasien terapi standard nyeri (TENS+NSAID) dan kelompok perlakuan dengan terapi standar nyeri (TENS+NSAID) + self-hypnosis. Sedangkan pada skor TMAS postest untuk kelompok perlakuan nilai rerata sebesar $10,93 \pm 3,35$ dan kelompok kontrol sebesar $12,73 \pm 2,13$ dengan nilai $p=0.020 \quad(p<0.05)$, yang berarti ada perbedaan yang bermakna antara kelompok perlakuan dengan kelompok kontrol pada tingkat 
kecemasan lansia penderita osteoartritis di RS. X Surakarta.

Tabel 3. Uji Perbedaan NRS (Nyeri) Dan TMAS (Cemas) Antara Kelompok Perlakuan Dan Kontrol Data Postest

\begin{tabular}{ccccc}
\hline Variabel & Kelompok & N & Rerata & $\boldsymbol{p}$ \\
\hline NRS Pretest & Perlakuan & 30 & $1.47 \pm 0.507$ & \multirow{2}{*}{0.198} \\
& Kontrol & 30 & $1.63 \pm 0.490$ & \\
TMAS Pretest & Perlakuan & 30 & $13.17 \pm 1.98$ & \multirow{2}{*}{0.952} \\
& Kontrol & 30 & $13.13 \pm 2.27$ & \\
\hline
\end{tabular}

Hasil penelitian ini menunjukkan bahwa terdapat pengaruh yang bermakna nyeri dan kecemasan antara kelompok kontrol pasien terapi standard nyeri (TENS+NSAID) dan kelompok perlakuan dengan terapi standar nyeri (TENS+NSAID) dan self-hypnosis.

Nyeri pada kelompok perlakuan lebih rendah dibanding dengan kelompok kontrol.Hal ini menunjukkan bahwa self-hypnosis lebih berpengaruh terhadap nyeri dan cemas daripada terapi standar tanpa self-hypnosis.

Menurut Isbagio (2001) nyeri menjadi gejala utama pada sendi yang mengalami osteoartritis. Rasa nyeri dapat mengganggu fungsi motorik, gangguan tidur, dan stres psikologis. Bila nyeri terjadi secara kronis, maka dapat menimbulkan gelisah, jantung berdebardebar, keringat dingin, keputusasaan, mudah tersinggung atau marah, menarik diri, dan depresi. Self-hypnosis dapat digunakan untuk menolong menajemen nyeri dan cemas (Lynn and Kirsch, 2006; Patterson, 2010).

\section{SIMPULAN}

Ada pengaruh Self-hipnosis terhadap intensitas nyeri lansia penderita osteoartritis dilihat dari hasil perbedaan yang bermakna nilai pretest dan posttest kelompok perlakuan nyeri lansia osteoartritis. Nilai rerata NRS (nyeri) kelompok perlakuan pretest sebesar $1,47 \pm 0,57$ dan posttest sebesar $0,97 \pm 0,72$ dengan nilai $p=$ $0.001(p<0.05)$. dan juga dilihat dari nilai rerata TMAS (cemas) kelompok perlakuan pretest sebesar $13,13 \pm 2,27$ posttest sebesar $10,93 \pm 3,35$ dengan nilai $p=0.00(p<0.05)$.

\section{DAFTAR PUSTAKA}

Blair, F.B. 2004. Instant Self-Hypnosis, How to Hypnosis Yourseld with Your Eyes Open. Illinois.

Holand, E. 2001. Hypnosis May Prevent Weakened Immune Status, Improve Health. Ohio.

Indonesian Rheumatology Association (IRA). 2014. Osteoarthritis. Available at: http://reumatologi.or.id (Accessed: 25 September 2016).

Isbagio, H. 2001. Struktur Rawan Sendi dan Perubahannya Pada Osteoarthritis, Cermin Dunia Kedokteran no. 129. Jakarta.

Komnas Lansia. 2013. Profil Penduduk Lanjut Usia. Jakarta : Komisi Nasional Lanjut Usia.

Lynn, S.J. and Kirsch, I. 2006. Depressio Essentials of Clinical Hypnosis : An Evidence-Based Approach', American Psychological Association.

Nurindra, Y. 2008. Self Hypnosis Kiat Praktis Melakukan Hypnosis ke Diri Sendiri. Available at: http://www.hipnotis.net/free-e-ebook-hipnotis.

Patterson, D.R. 2010. Clinical Hypnosis for Pain Control, American Psychological Association. Washington D.C.

Permana, F.H, Sumarwati, M., Rosyadi, I. 2009. Hubungan penurunan Fungsi Gerak Lansia Terhadap Strategi Koping Stres Lansia di Panti Jompo Welas Asih Kecamatan Singaparna Kabupaten Tasikmalaya, The Soedirman Journal of Nursing, 4(3), p. 5.

Sastroasmoro, A. and Ismail, S. 2006. Dasar-dasar Metodologi Penelitian Klinis. Jakarta: Sagung Seto. 
Soejono, C.H., Probosuseno and Sari, N.K. 2009. Depresi Pada Pasien Usia Lanjut, dalam Buku Ajar Ilmu Penyakit Dalam Jilid III. V. Jakarta: Pusat Penerbitan Departemen Ilmu Penyakit Dalam FKUI.

Sudiyanto, A. 2002. Simposium Depresi dan Penatalaksanaanya, Somatisasi pada Depresi. Surakarta 